\title{
Effect of Filler on Shear Strength and Electrical Conductivity in Epoxy Based Aluminium Bonded
}

\author{
Cahyo Yuniwantoro ${ }^{1}$, Eko Surojo ${ }^{1}$, Dharu Feby S. $^{1^{*}}$, Fitrian Imaduddin ${ }^{1}$ \\ ${ }^{1}$ Mechanical Engineering, Universitas Sebelas Maret \\ e-mail address : dharufs@staff.uns.ac.id
}

\section{Keywords:}

Epoxy; filler; Joining;

aluminium; electrical

conductivity

\begin{abstract}
:
Adhesive joint is one of the materials joining techniques using a low temperature with the help of polymer adhesives to connect a material. This connection is widely used in infrastructure, automotive and electronics industries. This research was conducted to determine the effect of filler on shear strength and electrical conductivity on epoxy-based aluminum connections. The fillers used were aluminum powder, iron powder, copper powder with a grain size of $0.071 \mathrm{~mm}$ each and nanogold particles in liquid form. This bond type used is a single lap joint with an end tab modification at the end of the connection. The highest shear strength value is in the joint without the addition of filler of $3.17 \mathrm{MPa}$ and the lowest value is in the connection with the addition of aluminum powder filler of 1.14 MPa. The highest value of electrical conductivity was obtained in epoxy mix with nanogold particle filler which was worth $13.1 \mathrm{~S} / \mathrm{m}$ and the value for epoxy without the addition of filler was not detected because the resistance was too large. This shows that the addition of filler has an effect on the value of shear strength, which is to reduce the value of the shear strength, while for testing the conductivity of electricity the addition of filler has an effect to provide electric properties on epoxy.
\end{abstract}

\section{INTRODUCTION}

In the development of technology and the industrial world, currently many new products consisting of a combination of new materials that need to be prepared in accordance with the specifications and characteristics [1]. Some techniques for connecting two or more materials can be done by bolts, rivets and welds [2]. This method has been found in many industries today, ranging from infrastructure, automotive, vehicles to the electronics industry. However, the connection technique above still has shortcomings from the design that takes up area to strength that can be reduced due to environmental conditions from time to time [1$3]$.

The latest discovery in overcoming the above deficiencies is by connecting the adhesive joints. This connection is in the form of joining two or more materials with epoxy-based adhesives [2]. Adhesive joints themselves are starting to be widely used in the industrial world as a way of joining materials because they are strong, do not have overdesign and can be used in metal and non-metal materials $[2,3]$.

The strength of the joint is in the glue that binds two or more joints. One of the most common types of glue is Epoxy. This epoxy is best used for joining metal materials because the nature of this epoxy in connecting metals is very unlikely to experience shrinkage [4]. High or low strength value of this connection is also influenced by the thickness and thinness of the epoxy layer, the thicker the epoxy layer, the higher the strength obtained and vice versa, the thinner the epoxy layer, the smaller the strength value of the connection [5].

This epoxy connection can be modified by adding powder material to the epoxy mixture. The purpose of this addition is to increase the value of thermal conductivity and mechanical strength at the joint. The addition of powder material is adjusted to the needs that will be met according to its characteristics [6,7]. Powder material which is often found as a mixture of 
epoxy glue itself is metal powder, including aluminum, nickel, gold and silver [7].

The effect of adding powder material to the epoxy glue can not only increase the value of thermal conductivity and mechanical strength, but also can increase the value of electrical conductivity at the connection [7]. The development of micro-electronic technology states that gradually electronic components change from isolated to integrated and modulated [8]. According to the study of Bar-Cohen et al [9], the stability of electronic devices will decrease by $10 \%$ when experiencing a temperature increase every $2^{\circ} \mathrm{C}$, so many electronics companies switch to using a connection with a mixture of epoxy and powder material as its components.

In previous studies only focused on one test that is mechanical strength with filler iron powder, aluminum powder and silica. The research shows that the addition of fillers mixed with epoxy increases the value of the shear strength.

This research will investigate the use of epoxy mixtures with filler aluminum powders, iron powders, copper powders and nanogold particle. This research is focused on the effect of powder material on epoxy mixes on shear strength and electrical conductivity on aluminum joints.

\section{EXPERIMENTAL}

The material used in this research is a series 1 aluminum plate which is used as an adhesion to joints, epoxy-based adhesives under the brand name Dextone and fillers with various aluminum powders, iron powders, copper powders with the grain size is $0.071 \mathrm{~mm}$ each and nanogold particle liquid.

Surface preparation is carried out on aluminum plates with a size of $40 \mathrm{~mm}$ x $150 \mathrm{~mm}$ using grade 75 sandpaper on both ends of the plate along the $40 \mathrm{~mm}$. This step aims to remove the smooth surface of the plate.

The process of making specimens is divided into 2 namely making shear strength test specimens and electrical conductivity test specimens. Making shear strength test specimens made 10 test specimens with details of 2 test specimens without the addition of filler to compare shear strength. Mixing epoxy with filler is done and affixed to aluminum plates with a thickness of $1 \mathrm{~mm}$ with a type of single lap joint connection. The making of electrical conductivity test specimens were made 5 specimens with details of four using the addition of filler and one specimen without the addition of filler which was then inserted in a beam-shaped silicone mold with a size of $44 \mathrm{~mm}$ x $10 \mathrm{~mm}$ x 10 $\mathrm{mm}$ such as shown in Figure 1 with a dry waiting time of 24 hours.

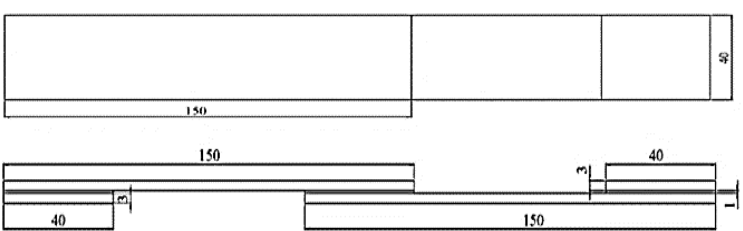

Figure 1. Shear strength test specimen
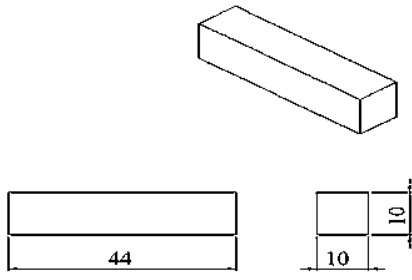

Figure 2. Electrical conductivity test specimens

\section{RESULT AND DISCUSSION}

\section{Shear Strength Testing}

In this test the observed data is the relationship between shear strength and filler variation with a $25 \%$ volume fraction. The test results can be seen as in Figure 3 .

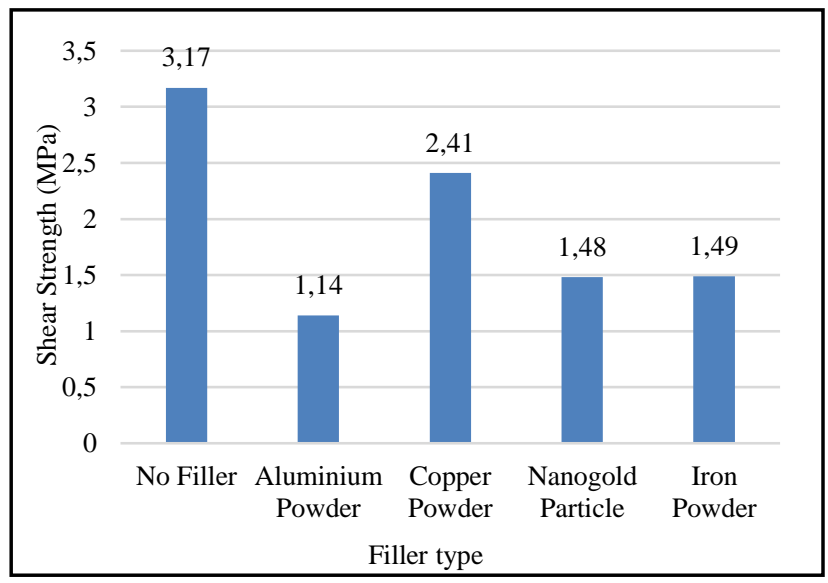

Figure 3. Graph of shear stress 
Figure 3. is a graph of the aluminum joint shear stress values with filler variations. From these data it is known that the highest shear stress value occurs in the aluminum connection without the addition of a filler with a value of $3.17 \mathrm{MPa}$. The lowest shear strength value occurs in the aluminum connection with the addition of aluminum powder type filler with a value of 1.14 MPa.

The decrease in shear stress is caused by several factors, including the grain size of the filler powder and the distribution of the filler $[10,11]$. The smaller the powder grain will be able to increase the strength value of the connection because smaller particles have a surface area that can encourage more effective transfer of stress [12-14]. The size of the connection strength due to the effect of the size of the powder diameter is also affected by its distribution, the more evenly distributed the powder, the better the results and vice versa $[10,11]$. This is shown in the results of research where the shear strength of the adhesive joint without the addition of filler has the highest strength value than the joint that gets the addition of filler. This condition is caused by the uneven distribution of fillers in the aluminum joints so hat the total surface area to increase the shear strength values of the joints is not met. Powder distribution the fill material can be seen in Figures 4, 5, 6 and 7.

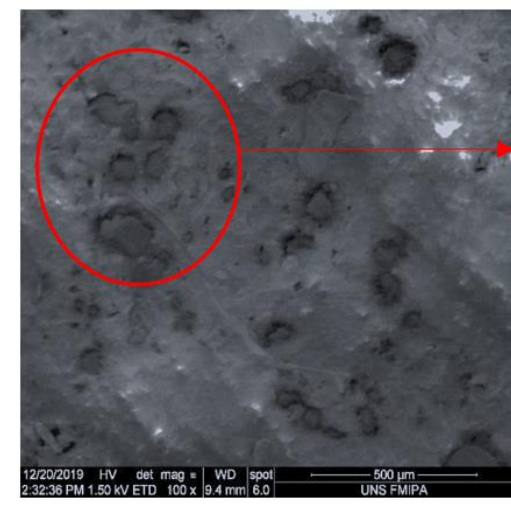

Uneven

powder grains

Figure 4. SEM surface of epoxy with copper powder filler

In Figure 4. seen the distribution of copper powder on the epoxy is not evenly distributed properly, causing a decrease in strength in the adhesive joint. The unequal distribution of copper powder is due to the incomplete mixing process so that the powder cannot be evenly distributed on the epoxy. This case also exists in epoxy mixtures with aluminum powder filler and iron powder as shown in Figures 5 and 6.

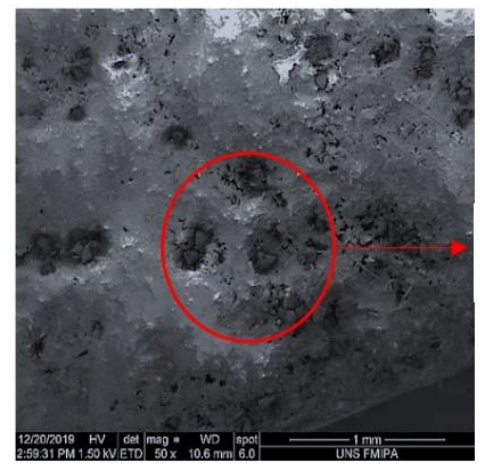

Uneven powder grains

Figure 5. SEM surface of epoxy with aluminum powder filler

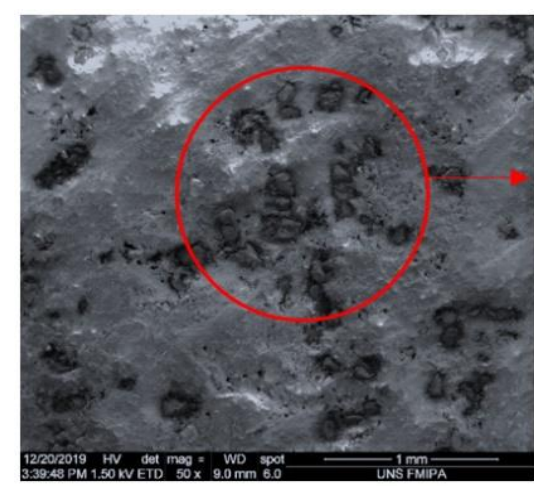

Uneven powder grains

Figure 6. SEM surface of epoxy with iron powder filler

The adhesive connection on epoxybased aluminum with nanogold particle filler has a difference from the adhesive joint with powdertype filler, this is because the filler used is liquid so that the distribution looks evenly but the strength of the joints decreases. This decrease in joint strength is due to porosity defects in the epoxy mixture with nanogold particle fillers. This porosity defect occurs due to air trapped in the epoxy mixture with nanogold particle filler when stirring occurs. This porosity causes the connection to break easily because trapped air causes an empty cavity as shown in Figure 7. 


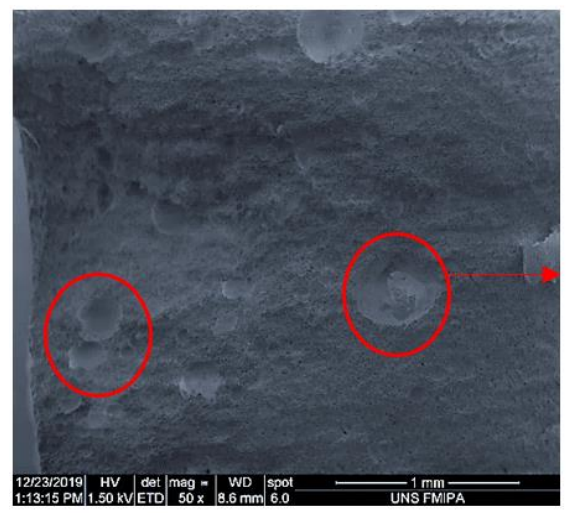

Porosity

defects

Figure 7. SEM of epoxy surfaces with nanogold particle fillers

Adhesive joints on epoxy-based aluminum plates without using a filler mixture have the highest strength but have disadvantages. The disadvantage that occurs in epoxy without this mixture is the creation of porosity defects that cause air cavity trapped inside the epoxy. This porosity defect occurs due to imperfect stirring so that air is trapped inside which causes a decrease in the strength of the joint. This porosity defect looks like in Figure 8.

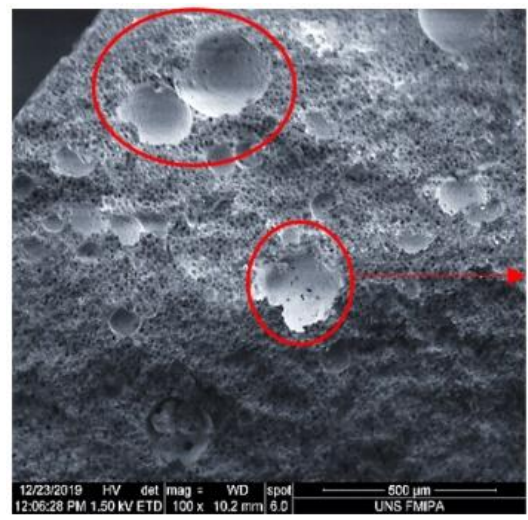

Porosity defects

Figure 8 . SEM of epoxy surface without mixture

\section{Electrical Conductivity Testing}

Electrical conductivity test results on epoxy-based aluminum connections show different results. This electrical conductivity test uses a device called a digital insulating resistance tester to obtain the value of the resistance of the test material followed by calculating with Formula 1. The results of the calculation of specific resistance are continued by calculating the electrical conductivity using Formula 2.

$$
\rho=\frac{R \cdot A}{L}
$$

Where:

$\rho=$ Specific Resistance $(\mathrm{G} \Omega \mathrm{m})$

$\mathrm{R}=$ Obstacle $(\Omega)$

$A=$ Surface Area $\left(\mathrm{m}^{2}\right)$

$\mathrm{L}=$ Specimen length $(\mathrm{m})$

$\sigma=\frac{1}{\rho}$

Where:

$\sigma=$ Electrical conductivity $(\mathrm{S} / \mathrm{m})$

$\rho=$ Specific Resistance $(\mathrm{G} \Omega \mathrm{m})$

The test results show different values of each material. This difference occurs due to differences in the mixture used in the test material. The test results look like in Figure 9.

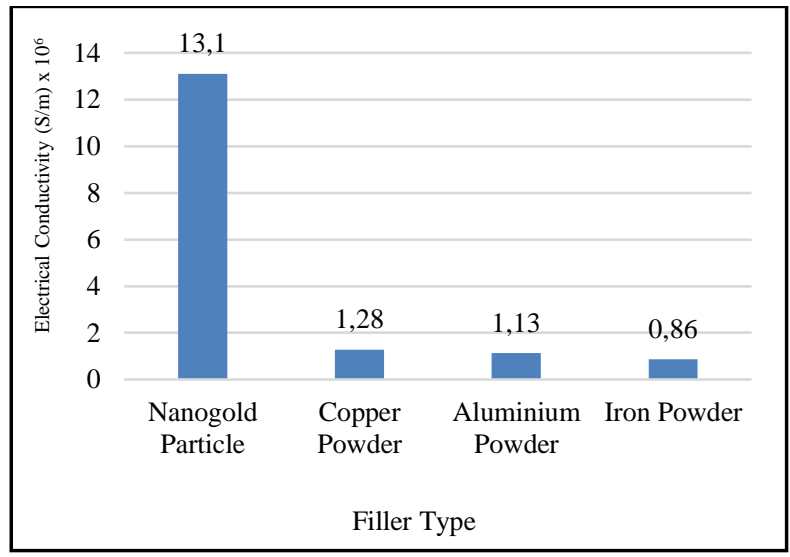

Figure 9. Graph of electrical conductivity test

The test results show that the best electrical conductivity value is owned by the epoxy mixture using the addition of fillers in the form of nanogold particles with a value of 1.32 $\mathrm{S} / \mathrm{m}$. The lowest value of the electrical conductivity is owned by the epoxy mixture using the addition of an iron powder filler with a value of $0.09 \mathrm{~S} / \mathrm{m}$. For epoxy material without the addition of filler, it shows the inability to conduct electricity because the results are undefined due to too much resistance.

The difference in the strength of electrical conductivity in each material is due to the difference in the filler used as a mixture in epoxy. Each filler material used has a different strength which is in accordance with the ability of each of these materials. The size of the ability 
to conduct electricity is influenced by several factors including the type of material, the amount of material and the even distribution of material [15].

The test results show the strength value of the electrical conductivity of the epoxy mixture sequentially from the strongest are nanogold particle, copper powder, aluminum powder, iron powder and epoxy without the addition of filler. This shows that the test results are in accordance with the ability of the filler material to conduct electrical properties where nanogold particle is one of the best materials to conduct electric current and iron powder is a material that is quite bad in conducting electric current.

The large difference in material grains also influences the power to conduct electric current. The smaller the shape of the material will further increase the value of the strength of electrical conductivity, and vice versa [12-14]. In testing the nanogold particle has the highest electrical conductivity strength because this type of material has good electrical properties and is also supported by the small grain of the nanogold particle, which causes better even distribution than other types of fillers with powder form. This test shows that epoxy is able to conduct electric current, but with the help of the addition of filler in it in the form of a material which basically has electrical properties. Good or bad the ability of epoxy to conduct electric current depends on the type of filler used in it as a mixture and with the right composition of the mixture so that it does not eliminate the power of the epoxy itself but can also conduct electric current.

\section{CONCLUSION}

This study shows that the addition of fillers to the epoxy mixture influences and is interconnected in the two types of research conducted. The addition of a filler decreases the strength of the connection but on the other hand, the addition of the filler gives the electrical conductivity of the epoxy mixture. Decreased shear strength caused by uneven distribution of powder.

\section{REFERENCES}

1. Banea, M. D., da Silva, L. F. M., and Campilho, R. D. S. G., Principles of Adhesive Bonding, Joining of Polymer-Metal Hybrid Structures: Principles and Applications, pp. 3-27, 2018.

2. Anam, K. and Purnowidodo, A., Effect of Filler Volume Fraction on Mechanical Strength and Failure Mode of Aluminium Bonded With Epoxy-Based Adhesive, AIP Conference Proceedings, Vol. 11(4), pp. 2746-2750, 2016.

3. Banea, M. D. and Da Silva, L. F. M., Adhesively Bonded Joints in Composite Materials: An Overview, Journal of Materials: Design and Applications, Vol. 223(1), pp. 118, 2009.

4. Tai, R. C. L. and Szklarska-Smialowska, Z., 1993, Effect of Fillers on The Degradation of Automotive Epoxy Adhesives in Aqueous Solutions - Part II The Microhardness Change and Delamination of Automotive Epoxy Adhesives in Distilled Water and $\mathrm{NaCl}$ Solutions, Journal of Materials Science, Vol. 28(22), pp. 6205-6210.

5. Paul, H., Ledford, N., Sauer, M., May, M., and Okamura, M., 2018, Assessment of Test Methods for Thick and Thin Layer Adhesive Joints Under High Rates of Loading, International Journal of Adhesion and Adhesives, Vol. 83(3), pp. 123-129.

6. Dadkan, S., Salari, S., Khakbiz, M., and Atai, M., 2014, Mechanical Properties of Dental Adhesives Containing Gold Nano Particles, Proceeding of 5th International Congress on Nanoscience \& Nanotechnology (ICNN2014), (5), pp. 22-24.

7. Qiao, W., Bao, H., Li, X., Jin, S., and Gu, Z., 2014, Research on Electrical Conductive Adhesives Filled With Mixed Filler, International Journal of Adhesion and Adhesives, Vol. 48, pp. 159-163.

8. Ponce, M., Martínez, A. J., Correa, J., Cotorogea, M., and Arau, J., 2006, HighEfficient Integrated Electronic Ballast For Compact Fluorescent Lamps, IEEE Transactions on Power Electronics, Vol. 21(2), pp. 532-542.

9. Fu, Y. X., He, Z. X., Mo, D. C., and Lu, S. S., 2014, Thermal Conductivity Enhancement with Different Fillers for Epoxy Resin Adhesives, Applied Thermal Engineering, Vol. 66(2), pp. 493-498.

10. Khoramishad, H. and Razavi, S. M. J., 2014, Metallic Fiber-Reinforced Adhesively Bonded Joints, International Journal of Adhesion and Adhesives, Vol. 55, pp. 114-122.

11. Nemati Giv, A., Ayatollahi, M. R., Razavi, S. M. J., and Khoramishad, H., 2018, The Effect 
of Orientations of Metal Macrofiber Reinforcements on Mechanical Properties of Adhesively Bonded Single Lap Joints, Journal of Adhesion, Vol. 94, pp. 541-561.

12. Reynaud, E., Jouen, T., Gauthier, C., Vigier, G., and Varlet, J., 2001, Nanofillers in Polymeric Matrix: A Study on Silica Reinforced PA6, Polymer, Vol. 42, pp. 87598768.

13. Sumita, M., Shizuma, T., Miyasaka, K., and Ishikawa, K., 1983, Effect of Reducible Properties of Temperature, Rate of Strain, and Filler Content on the Tensile Yield Stress of Nylon 6 Composites Filled with Ultrafine Particles, Journal of Macromolecular Science, Part B, Vol. 22, pp. 601-618.

14. Buggy, M., Bradley, G., and Sullivan, A., 2005, Polymer-Filler Interactions in Kaolin/Nylon 6,6 Composites Containing a Silane Coupling Agent, Composites Part A: Applied Science and Manufacturing, Vol. 36, pp. 437-442.

15. Nemati Giv, A., Ayatollahi, M. R., Ghaffari, S. H., and da Silva, L. F. M., 2018, Effect of Reinforcements at Different Scales on Mechanical Properties of Epoxy Adhesives and Adhesive Joints: A Review, Journal of Adhesion, Vol. 94, pp. 1082-1121. 